\title{
Airway management of patient with traumatic cricotracheal transection
}

Nunes R.R. ${ }^{1}$, Lopes C.G. ${ }^{2}$, Fernandes M.B.C. ${ }^{1}$, Cavalcante S.L.F. ${ }^{1}$, Pontes D.M. ${ }^{1}$, Nunes Filho R.R. ${ }^{1}$

${ }^{1}$ Hospital Geral de Fortaleza, Dept of Anaesthesiology, Fortaleza, Brazil, ${ }^{2}$ Hospital Sao Carlos,

Dept of Anaesthesiology, Fortaleza, Brazil

Background: Cricotracheal transection due to cervical trauma is a rare and usually fatal event. Fast and efficient airway management is essential to prevent acute ventilatory obstruction.

Case report: A 23-year-old patient without comorbidities experienced cervical trauma from a kitesurf line, with total section of the trachea between the cricoid cartilage and the first tracheal ring, but no injury to the esophagus, marrow or large vessels. Upon admission, the patient was awake, oriented and without hemodynamic compromise, communicating by gestures and breathing spontaneously by the tracheal orifice $\left(\mathrm{SpO}_{2}=97 \%\right)$. Exploratory cervicotomy under general anesthesia was indicated. The patient was preoxygenated via the sectioned trachea, followed by direct esophageal compression and orotracheal intubation, with the extremity of the tube guided into the trachea with Magill forceps. After tracheoplasty, tracheostomy was performed between the third and fourth tracheal rings. When transferred to post-anesthesia recovery care, the patient was breathing spontaneously.

Discussion: In view of the patient's good hemodynamic and ventilatory status, conventional anesthesia and orotracheal intubation were adopted, facilitating tracheoplasty.
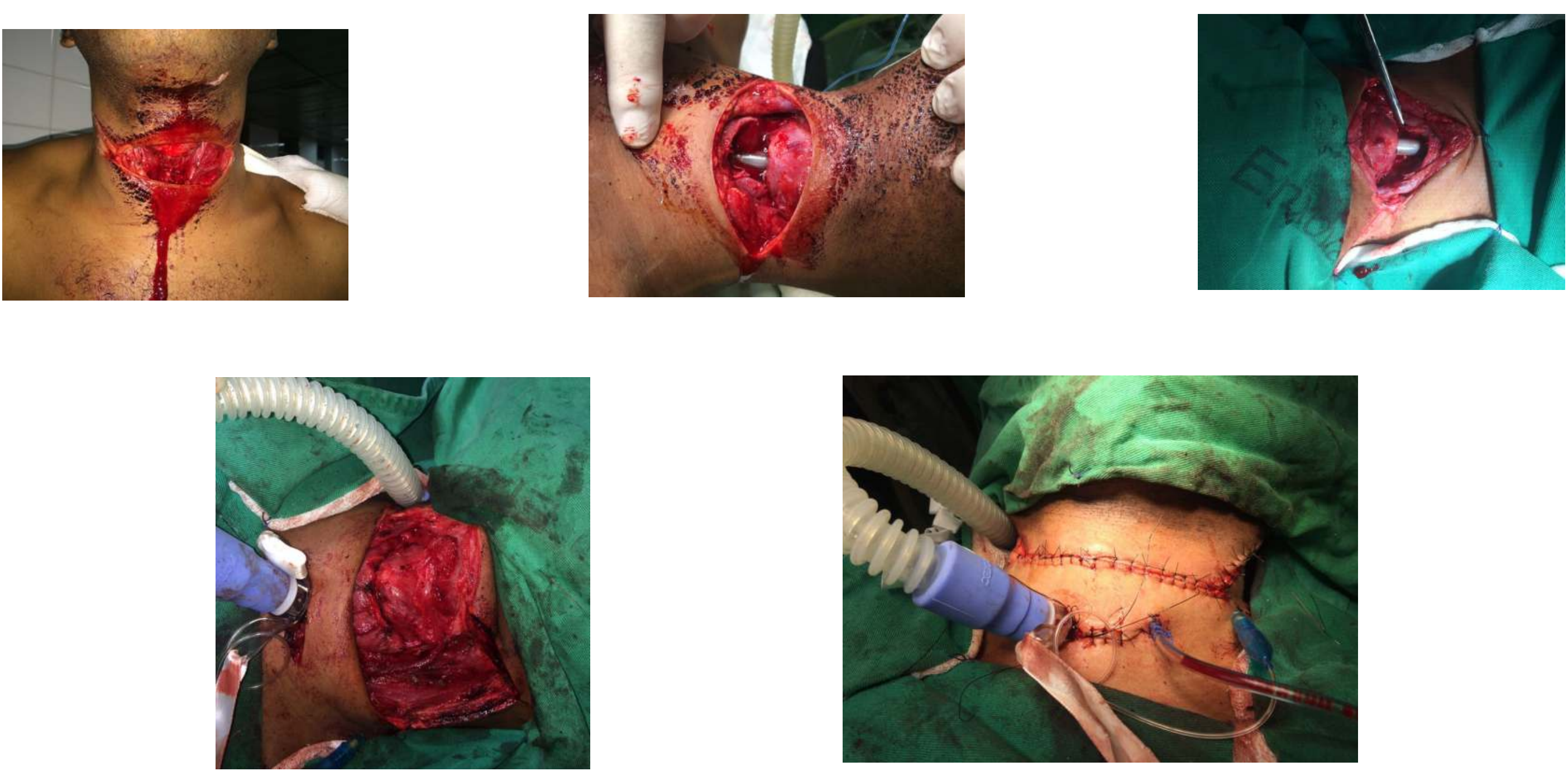

\section{References:}

1.Singh GB, Kummar R, Verma N et al. A Rare Case of Survival after Complete Traumatic Cricotracheal Separation. Case Reports in Otolaryngology. 2012;1-3.

2.Valerio $P$, Ivan $M$, Francisco $R$ et al. Surviv al after traumatic complete laryngotracheal transection. Am j emerg med. 2008;26:837.e3-837.e4. 